\title{
Control of lysozyme gene expression in differentiating HL-60 cells
}

\author{
Daniel A. Polansky, Angela Yang, Kevin Brader and D. M. Miller* \\ Simpson Memorial Institute, Department of Internal Medicine, University of Michigan. \\ Ann Arbor, Michigan
}

Received 15 January 1984; accepted for publication 12 September 1984

SUMmary. We have investigated the control of lysozyme gene expression in HL-60 cells induced to differentiate into macrophage-like cells with phorbol myristate acetate (PMA). Differentiation, as evidenced by cellular adherence, and morphological changes corresponded temporally to an increase in nonspecific esterase activity. The lysozyme concentration in the medium of uninduced HL-60 cells was $10 \mu \mathrm{g} / 10^{7}$ cells, increasing to a maximum of $46 \mu \mathrm{g} / 10^{7}$ cells after $48 \mathrm{~h}$ incubation with PMA (16 $\mathrm{nM}$ ). At $72 \mathrm{~h}$ the lysozyme concentration decreased to $16 \mu \mathrm{g} / 10^{7}$ cells. Intracellular lysozyme activity remained constant throughout differentiation.

If HL-60 cells were exposed to PMA for $24 \mathrm{~h}$, washed, then maintained in normal medium, they differentiated normally, confirming their irreversible commitment to differentiate. The increase in lysozyme secretion by these cells, however, is markedly blunted suggesting that continued PMA treatment of differentiated cells is required for their secretion of lysozyme. There is no change in the rate of extracellular degradation of lysozyme during differentiation.

The level of lysozyme mRNA does not correlate directly with the amount of lysozyme secreted into the medium. Hybridization of uninduced HL-60 cell RNA with a chicken lysozyme cDNA probe demonstrates moderate hybridization. There is a modest (five-fold) increase in lysozyme mRNA between 0 and $36 \mathrm{~h}$ of exposure to PMA, corresponding to the burst of lysozyme secretion by these cells. The lysozyme mRNA decreases to a level which is lower than the original baseline by $72 \mathrm{~h}$, when the cells are still secreting substantial amounts of lysozyme.

These data suggest that both transcriptional and post-transcriptional controls are operative in the control of lysozyme gene expression during the differentiation of HL-60 cells. They also imply that lysozyme secretion is not a necessary component in the macrophage-monocyte differentiation of these cells.

* Scholar, Leukemia Society of America

Correspondence: Dr D. M. Miller, Comprehensive Cancer Center. University of Alabama in Birmingham. Birmingham, Alabama 35294, U.S.A. 
Lysozyme (muramidase) is secreted by both normal and leukaemic cells of the macrophage/ monocyte lineage. We have studied the control of expression of the lysozyme gene in differentiating HI-60 cells (Collins et al, 1977; Gallagher et al, 1979), a promyelocytic leukaemia cell line which may be induced to differentiate into either granulocytes or macrophages (Collins et al, 1979. 1980); Tarella et al, 1982; Breitman et al, 1980, 1981; Olsson \& Olofsson, 1981; Fontana et al, 1980; Olsson et al, 1982; Todd et al, 1981; Huberman et al, 1981; Abraham \& Smiley, 1981; Rovera et al, 1979, 1980; Huberman \& Callahan, 1979). Although the macrophage-like cells which are induced by induction with PMA are not functionally normal macrophages (Newburger et al, 1981), they do demonstrate increased secretion of lysozyme. Lysozyme is the predominant newly synthesized protein secreted activated macrophages (Gordon et al, 1974). The mechanism of this increase has been previously uninvestigated.

Secretion of large amounts of lysozyme by myelomonocytic leukaemia cells is reflected by the large quantities of lysozyme in the urine of these patients with myelomonocytic leukaemia (Osserman \& Lawlor, 1966; Catovsky et al, 1971). Lysozyme may also be found in substantial quantities in normal granulocytes or CGL cells, but is not commonly secreted by these cells (Pinkus \& Said. 1977).

We were able to take advantage of the sequence homology between chicken egg white lysozyme and human lysozyme (Dayhoff, 1973: Canfield, 1963) to use a chicken lysozyme cDNA plasmid (Plys 6) (Buell et al, 1979) to study expression of human lysozyme in differentiating HL-60 cells. We have shown that there is specific cross hybridization between the chicken lysozyme cDNA probe and the human lysozyme gene allowing us to utilize this probe to assay human lysozyme mRNA.

We have addressed the question of whether increased secretion of lysozyme is directly related to the differentiation of the HL-60 cells to macrophage-like cells or whether it is a distinct event. We have also investigated the question of whether increased secretion of lysozyme by these cells represents increased transcription of the lysozyme gene or whether post-transcriptional events may play a role as well.

\section{MATERIALS AND METHODS}

HL-60 cells were a gift of Dr Robert Gallo (Collins et al, 1977). They were grown to a concentration of $1 \times 10^{6}$ cells per $\mathrm{ml}$ in RPMI-1640 (Gibco) with $10 \%$ fetal bovine serum, penicillin (100 units/ml) and streptomycin $(100 \mu \mathrm{g} / \mathrm{ml})$.

PMA was added to a final concentration of $16 \mathrm{mM}(10 \mu \mathrm{g} / \mathrm{ml})$ in $0.01 \%$ dimethyl sulphoxide (DMSO), (a DMSO concentration lower than that required to induce differentiation of these cells). For experiments involving incubation with DMSO cells were incubated in a similar fashion with a final concentration of $2 \%$ DMSO.

For each experiment the cells were resuspended in fresh medium. Cells used for mRNA extraction were grown in $50 \mathrm{ml}$ sterile polypropylene tubes to reduce adherence. Cells used for the adherence and lysozyme assay were grown in $16 \mathrm{~mm}$ diameter wells (Costar Culture Cluster Wells).

Lysozyme assay. Lysozyme activity was assayed by the procedure of Litwack (Solsted \& 
Martinez, 1978). The reaction mixture contained one-tenth volume cell medium in Micrococcus lysodeikticuticus solution $\left(25 \mathrm{mg} / \mathrm{ml} M\right.$. lysodeikticuticus, $1 \% \mathrm{NaH}_{2} \mathrm{Cl}, 0.2 \mathrm{M}$ $\mathrm{NaPO}_{4}, \mathrm{pH} 6 \cdot 2$ ). Lysozyme activity was assayed as a decrease in optical density at $450 \mathrm{~nm}$ per minute from 30 to $90 \mathrm{~s}$. Egg-white lysozyme was used as a standard.

These values were confirmed by the 'lyso-plate' lysozyme assay (Yam et al, 1971).

Cell adherence. Differentiation of HL-60 cells to macrophage-like cells was assayed by quantitating adherence to plastic tissue culture wells. Log phase cells were centrifuged and resuspended in fresh medium with 16 nM PMA. Cell suspensions were placed in wells at a concentration of $1 \times 10^{6} \mathrm{cell} / \mathrm{ml}$. Nonadherent cells were counted in the supernatant after washing. Adherant cells were quantitated by lysis and quantitation of nuclei. The sum of adherent and nonadherent cells counted correlated well with the original number of cells placed in each well. Viability was documented by Trypan Blue staining.

Nonspecific esterase staining. Cells were also grown under identical conditions in tissue culture tubes to which they did not adhere. For each time point, cells were centrifuged and analysed for non-specific esterase (NSE) using alpha naphthyl butyrate as a substrate (Yam et al, 1971).

RNA extraction. RNA was extracted as previously described (Miller et al, 1978). Vanadium ribonucleoside was utilized as an RNAse inhibitor (Berger \& Birkenmeier, 1979). Approximately 100 mg RNA was obtained from $10^{8}$ cells.

Liquid RNA-cDNA hybridization. Liquid RNA-DNA hybridizations were performed as described by Benz et al (1977). Hybridizations were performed in $50 \%$ formamide, $0.05 \mathrm{M}$ Hepes, pH 7.1, $5 \mathrm{~mm}$ EDTA, $0.5 \mathrm{M} \mathrm{NaCl}, 7 \mu \mathrm{g} / \mathrm{ml}$ E. coli DNA, and $0.05 \mu \mathrm{g} / \mathrm{ml} \mathrm{E}$. coli tRNA with $25 \mathrm{mg} / 160 \mu \mathrm{l}$ total RNA and $0.51 \mathrm{pg} / 160 \mu \mathrm{l}^{32} \mathrm{P}$ nick translated plasmid (Plys $63 \times 10^{7}$ $\mathrm{cpm} / \mu \mathrm{g})$. Hybridization was quantitated by $S_{1}$ nuclease digestion. Lysozyme sequences were detected by hybridization to the Plys 6 chicken lysozyme cDNA probe kindly supplied by Dr Robert Schimke.

\section{RESULTS}

PMA induced differentiation of HL-60 cells was assayed by cellular adherence to plastic. The number of adherent cells correlated directly with the number of cells which had differentiated to macrophages morphologically. A slight increase in the number of adherent cells occurred within $12 \mathrm{~h}$, with a rapid rise between 24 and $48 \mathrm{~h}$. Maximum adherence occurred at $48 \mathrm{~h}$ and continued for approximately $24 \mathrm{~h}$. Less than $3 \%$ of uninduced cells adhered to the plate (see Fig 1) throughout the experiment. Increase in nonspecific esterase staining correlated temporally with the increased adherence of the differentiating cells (data not shown). If the PMA was removed at $24 \mathrm{~h}$ and the incubation continued in the absence of PMA, differentiation continued at a rate not significantly different from that of cells with continuous exposure to PMA.

Lysozyme secretion, however, did not follow the same pattern (Fig 2). If the differentiating HL-60 cells were continuously exposed to PMA lysozyme secretion reached a maximum of 46 $\mu \mathrm{g} / 10^{7}$ cells at $48 \mathrm{~h}$, then declined to $15 \mu \mathrm{g} / 10^{7}$ cells at $70 \mathrm{~h}$. This decrease was consistently observed, and most likely represents decreased synthesis of new lysozyme and degradation of 


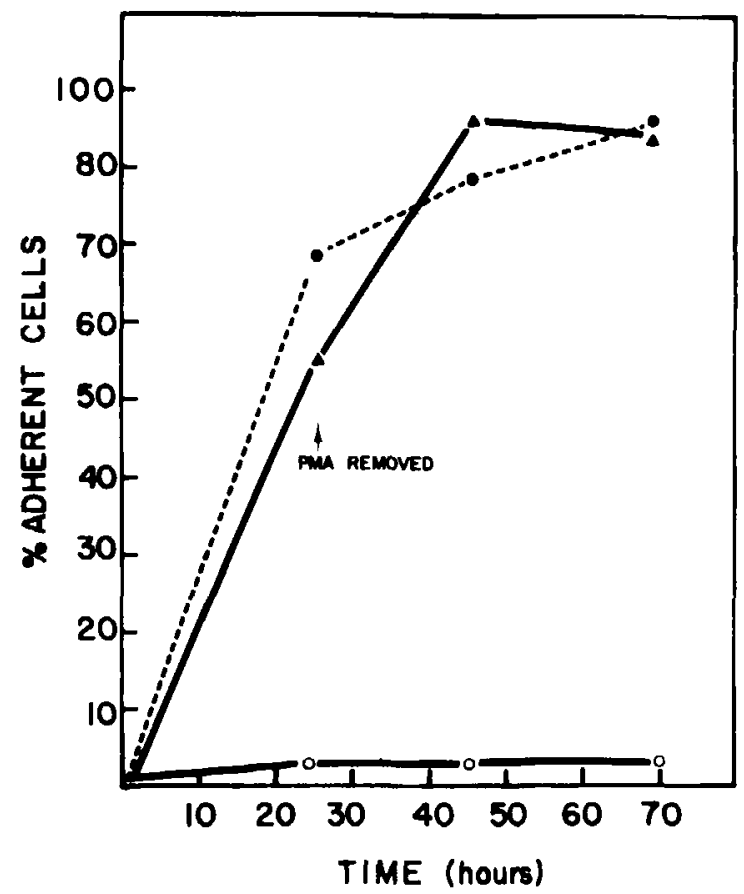

Fig 1. Macrophage differentiation of HL-60 cells treated with phorbol myristate acetate. Differentiation was quantitated as adherence to tissue culture plastic. $\bullet$ Continuous PMA treatment; $\Delta, 24 \mathrm{~h}$ PMA treatment: 0 , no PMA.

previously secreted lysozyme. The maximal increase in lysozyme activity occurred 6-12 h after the maximal differentiation. The uninduced cells did not increase their level of intracellular lysozyme or the amount of lysozyme secreted into the medium. HI- 60 cells which were exposed to PMA for only $24 \mathrm{~h}$ secreted much less lysozyme, reaching a peak of 21 $\mu \mathrm{g} / 10^{7}$ cells at $72 \mathrm{~h}$. Intracellular lysozyme levels did not change significantly during either continuous or $24 \mathrm{~h}$ exposure. Cell number and viability were virtually identical for those cells treated continuously and those treated for only $24 \mathrm{~h}$. Uninduced control cells demonstrated a constant level of lysozyme in the medium at $10 \mu \mathrm{g} / 10^{7}$ cells.

To test for specific degradation of extracellular lysozyme by products of differentiating cells we measured the loss of exogenous lysozyme activity added to the medium of phorbol treated and untreated $\mathrm{HI}_{r}-60$ cells after centrifugation and removal of the cells. As is obvious from Fig 3 the rate of degradation is identical in the medium of differentiated and nondifferentiated cells suggesting that enzymatic catabolism is not responsible for the altered level of lysozyme activity which we observe.

Considerable sequence homology exists between the chicken and human lysozyme molecules. The amino acid sequences of both of these are known (Dayhoff, 1973; Buell et al, 1979 ) allowing us to make a direct comparison. Seventy-eight of 130 amino acids (60\%) are identical, indicating a moderate degree of homology. This predicts that specific cross hybridization might occur between the chicken and human lysozyme nucleic acid sequences. 


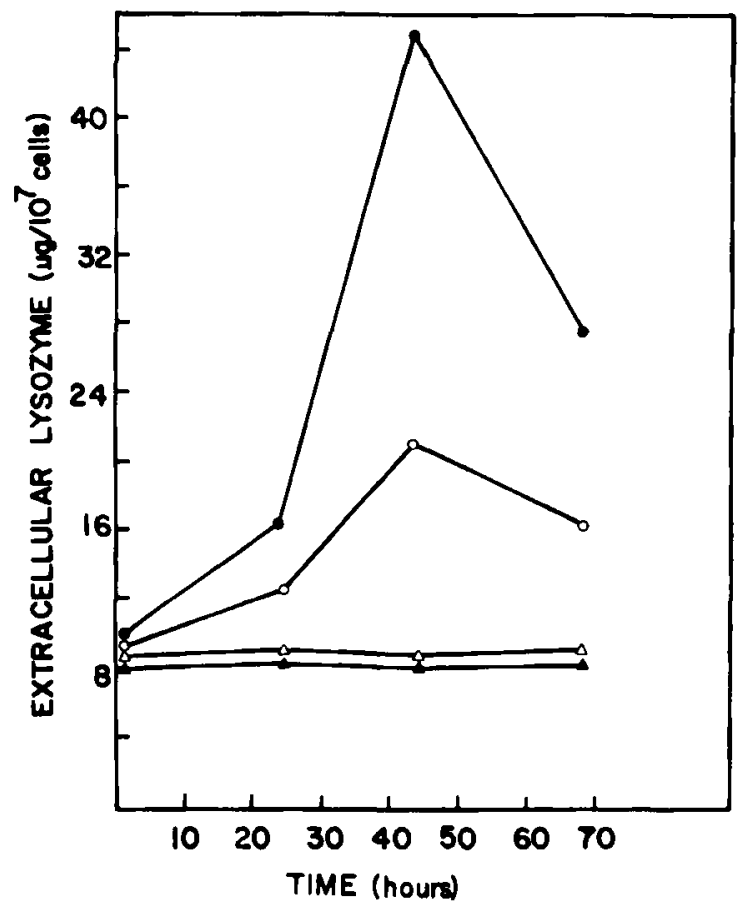

Fig 2. Lysozyme secretion by cells induced to differentiate by phorbol myristate acetate. Lysozyme was measured by turbidometric method as described in Methods and quantitated as chicken egg white lysozyme equivalents. $\bullet$. Continuous PMA treatment; 0,24 h PMA treatment; $\triangle$, no PMA: $\triangle$, DMSO treatment.

We tested this prediction by performing melting curve analysis of hybrids between nick-translated Plys 6 and RNA from the cells of a patient with myelomonocytic leukaemia who was secreting large amounts of lysozyme. The melting curve analysis is shown in Fig 4. The Tm is $68^{\circ}$, exactly that of a globin cDNA-globin mRNA hybrid determined in this system in a parallel experiment. A plasmid-E. coli RNA hybridization revealed less than $5 \%$ reannealing at the time the melting curve was performed. The sharp melting curve documents specific cross hybridization and demonstrates the usefulness of this probe for our experiments.

Quantitative analysis of lysozyme mRNA was performed by liquid hybridization. Liquid RNA-cDNA plasmid hybridization demonstrated a moderate level of hybridization with total RNA extracted from uninduced cells, with a five-fold increase in hybridization with total RNA extracted from cells exposed to PMA for $32 \mathrm{~h}$. A relatively low level of hybridization (one half that of uninduced cells) was observed with RNA from cells exposed to PMA for $72 \mathrm{~h}$ (see Fig 5). This indicated that the level of lysozyme-specific RNA is relatively high in uninduced cells. despite the fact that these cells are secreting little or no lysozyme. After treatment with PMA for $50 \mathrm{~h}$ the level of lysozyme-specific RNA increases five-fold, simultaneous with the increase of lysozyme secretion. At $72 \mathrm{~h}$, however, the level of lysozyme RNA has decreased dramatically despite the fact that lysozyme continues to be secreted at relatively high levels. 


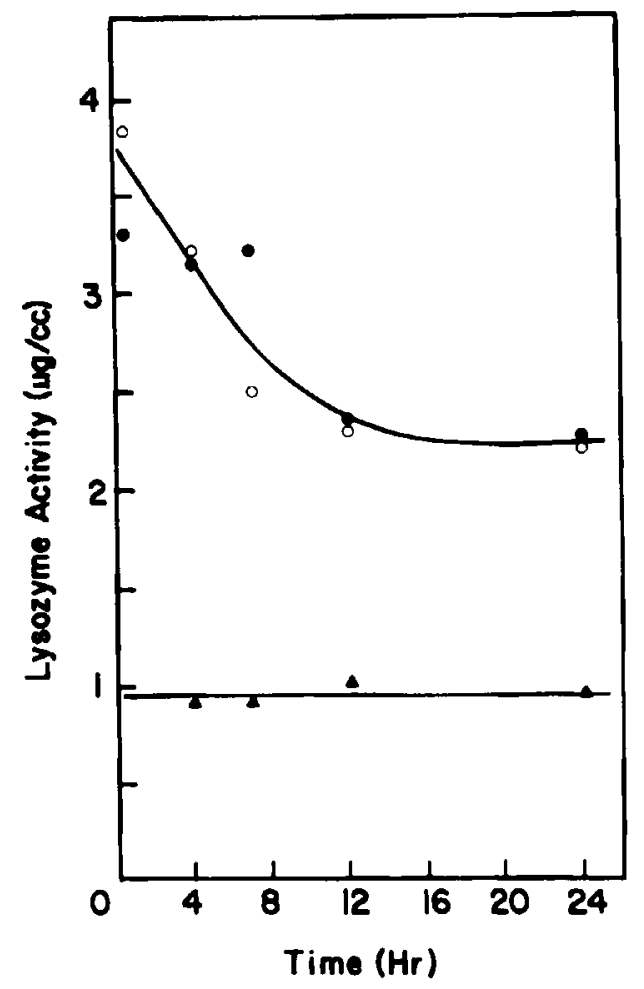

Fig 3. Enzyme activity of chicken egg white lysozyme added to medium of HL-60 cells treated with phorbol myristatc acetate. Lysozyme $(4 \mu \mathrm{g} / \mathrm{ml})$ was added to medium from HL- 60 cells treated with PMA after removal of all cells. Residual lysozyme activity was assayed with both the turbidometric and lyso-plate assays and expressed as chicken egg white lysozyme equivalents. $\bigcirc$. No PMA treatment: $\bullet$. 24 h PMA treatment; $\triangle$, no PMA treatment; no added lysozyme.

RNA dot blot hybridization confirmed this result demonstrating a low level of hybridization of the chicken lysozyme cDNA probe to total RNA extracted from HI-60) cells after 0 and $74 \mathrm{~h}$ of exposure to PMA. Total RNA from cells at $54 \mathrm{~h}$ of exposure to PMA demonstrated considerable hybridization to the chicken lysozyme cDNA probe.

The relationship between lysozyme RNA concentration and lysozyme gene expression is documented in Table I. Clearly the ratio of lysozyme RNA to lysozyme remains constant during differentiation of these cells, implying strict transcriptional control at this stage. Following differentiation, however, the level of lysozyme secretion falls more slowly than lysozyme mRNA implicating post-transcriptional control of expression. There is no major increase in the level of lysozyme mRNA which might explain its prolonged secretion.

\section{DISCUSSION}

HL-60 cells treated with PMA differentiate to morphologically normal macrophages (Todd $e t$ al, 1981). Numerous enzymatic and metabolic alterations have been noted during this 


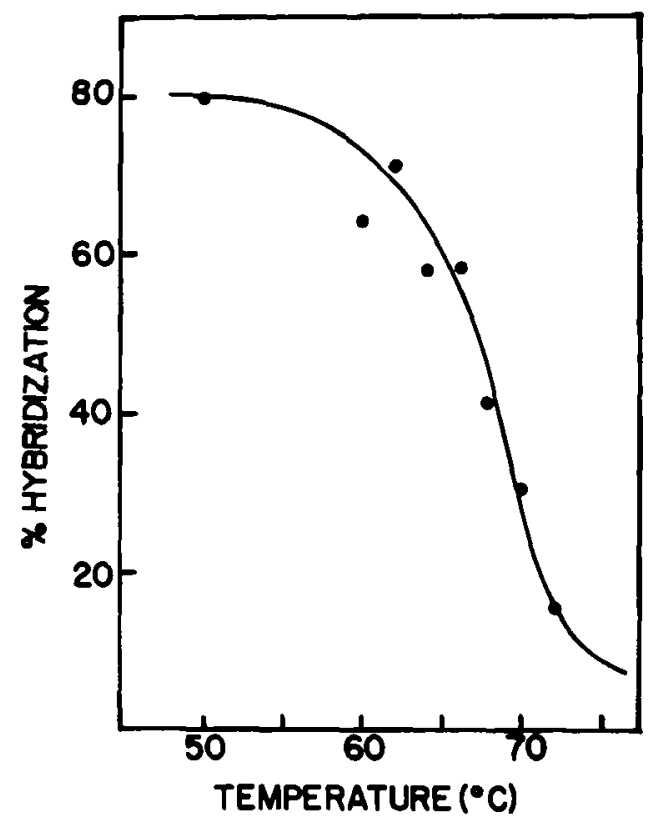

Fig 4. Melting curve of Plys 6 plasmid-myelomonocytic leukaemia RNA hybrids. Hybrids were formed for $48 \mathrm{~h}$ then temperature elevated at a rate of $1 \% / 30 \mathrm{~min}$. Per cent hybridization was assayed by $S_{1}$ digestion.

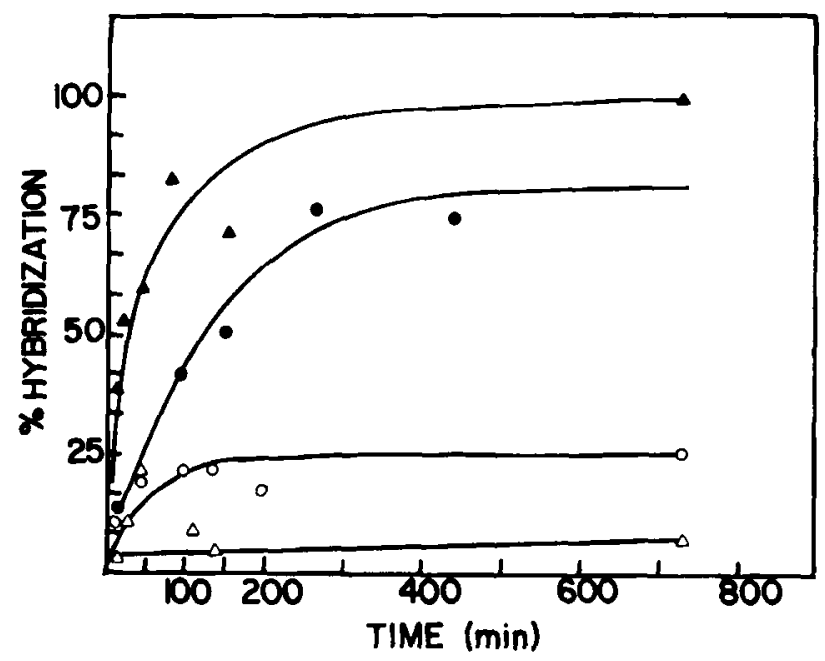

Fig 5. Hybridization of nick-translated plasmid Plys 6 to HL-60 RNA isolated at various times during macrophage differentiation. Nick-translated $\left(8 \times 10^{7} \mathrm{cpm} / \mathrm{mg}\right)$ probe was hybridized to HL-60 RNA. Hybridization was assayed by $S_{1}$ digestion. $\bullet, \circ \mathrm{h}$ PMA treatment; $\triangle, 32 \mathrm{~h}$ PMA treatment; $0,72 \mathrm{~h}$ PMA treatment; $\triangle$, tRNA. 
Table I. Relationship between lysozyme secretion and relative lysozyme mRNA concentration during differentiation of HL-60 cells

Time of induction (h)

\begin{tabular}{lcrr} 
& & 36 & \multicolumn{1}{c}{72} \\
\hline Secreted lysozyme $\left(\mu \mathrm{g} / 5 \times 10^{6}\right.$ cells $)$ & $5 \cdot 0$ & $23 \cdot 2$ & $7 \cdot 0$ \\
Intracellular lysozyme $\left(\mu \mathrm{g} / 5 \times 10^{6}\right.$ cells $)$ & $<2 \cdot 0$ & $<2 \cdot 0$ & $<2 \cdot 0$ \\
Relative lysozyme mRNA concentration & $1 \cdot 00$ & $5 \cdot 9$ & 0.5 \\
Ratio of secreted lysozyme to relative lysozyme mRNA level & $5 \cdot 0$ & $3 \cdot 9$ & $13 \cdot 5$ \\
\hline
\end{tabular}

* The relative lysozyme mRNA concentration was calculated from the ratio of initial slopes of the hybridization curves.

differentiation. Increased nonspecific esterase activity, increased cellular adherence, increased responsiveness to phagocytic stimuli, as well as increased secretion of lysozyme accompany HL-60 cell differentiation. The mechanism of these alterations is unclear.

We have investigated the mechanism of one of these changes, the increased secretion of lysozyme during PMA-induced differentiation of HL-60 cells. We were particularly interested in the question of whether lysozyme secretion is a function of the macrophage-monocyte differentiation of these cells or whether it results from continued stimulation of differentiated cells. We were also interested in whether increased expression of the lysozyme gene (as evidenced by increased lysozyme secretion by the differentiated cells) was mediated at the transcriptional or post-transcriptional level.

HL-60 cells treated with PMA for $24 \mathrm{~h}$, or less, are clearly irreversibly committed to differentiate. This has been demonstrated for other inducing agents, as well. We confirmed this observation by documenting that removal of PMA at $24 \mathrm{~h}$ did not influence differentiation of these cells. Peak stimulation of lysozyme secretion, however, was markedly decreased. This result implies that increased secretion of lysozyme by the differentiated HL-60 cells is dependent on continued stimulation of the cells by PMA, analogous to activation of mature macrophages by PMA. It also implies that lysozyme secretion is a marker for differentiated cells rather than a necessary component of differentiation. This conclusion is supported by the observation that the increase in lysozyme secretion occurs $12-24 \mathrm{~h}$ after the increase in adherence of these cells. The increase in nonspecific esterase, on the other hand, occurs simultaneously with the differentiation of the cells, implying that this alteration is a function of differentiation. Thus, there may be two sets of altered gene functions in cells induced to differentiate with PMA, those occurring as a direct result of differentiation, and those occurring as a result of continued stimulation of differentiated cells.

Our data suggest that the initial increase of lysozyme expression is directly related to increased lysozyme gene transcription with the ratio lysozyme mRNA to extracellular lysozyme activity remaining constant during a five-fold increase of both. The significant level of lysozyme mRNA in the uninduced cells is not surprising considering the baseline level of intracellular lysozyme and the low level of lysozyme secretion by uninduced cells. 
More surprising, however, is the extremely low level of lysozyme mRNA (less than half that of uninduced cells) in cells treated with PMA for $72 \mathrm{~h}$. This result suggests that PMA induces an initial burst of lysozyme mRNA synthesis in differentiated cells which lasts less than $24 \mathrm{~h}$, followed by a very low level of lysozyme transcription. Increased secretion must also occur after a short delay. Pulse-chase experiments (now in progress) should elucidate the relative importance of mRNA stability in these alterations.

The persistence of significant lysozyme secretion in terminally differentiated cells with very low levels of lysozyme mRNA may reflect continued translation of low levels of lysozyme mRNA by these cells. It is unlikely to reflect increased stability of secreted lysozyme since degradation of lysozyme activity occurs at a similar rate in medium from differentiated and nondifferentiated cells.

PMA may have two sites of action. The transcriptional alterations of the lysozyme gene imply that it alters transcription of the lysozyme (and probably many other) genes. It must also act at the cell membrane, where it is specifically bound (Shoyab \& Todaro, 1980: Sando et al, 1981; Driedger \& Blumberg, 1980) altering secretion of lysozyme and other molecules. This mixed transcriptional/post-transcriptional mechanism of gene control may be more common than is currently suspected. It may play an important role in altered expression of 'tumour marker' genes in malignant cells.

\section{ACKNOWLEDGMENTS}

We thank Dr Robert Schimke for providing the Plys 6 plasmid and Drs George Shaw and Prakash Bhuta for helpful discussions. We acknowledge the assistance of Ms Sue Vigo in preparing the manuscript.

Supported by Grants from Childrens Leukemia Foundation of Michigan. Leukemia Society of America and American Cancer Society.

\section{REFERENCES}

Abrahm, J.L. \& SmiLey, R. (1981) Modification of normal human myelopoiesis by 12-0-tetradecanoylphorbol-13-acetate (TPA). Blood. 58, 1119-1126.

Benz, E.J., Jr, Geist, C., Steggles, A.. Barker, J. \& NeINHUIS, A. (1977) Hemoglobin switching in sheep and goats. Journal of Biological Chemistry, 252, 1908-1916.

BeRger, S.L. \& BirkenMeier, C.S. (1979) Inhibition of intractable nucleases with ribonucleoside-vanadyl complexes: isolation of messenger ribonucleic acid from resting lymphocytes. Biochemistry, 18, 5143-5249.

Breitman, T.R., Collins, S.J. \& Keene, B.R. (1981) Terminal differentiation of human promyelocytic leukemic cells in primary culture in response to retinoic acid. Blood. 57 , 1000-1004.

Breitman, T.R., Selonick, S.E. \& Collins, S.J. (1980) Induction of differentiation of the human promyelocytic leukemia cell line (HL-60) by retinoic acid. Proceedings of the National Academy of Sciences of the United States of America, 77, 2936-2940.

Buell, G.N., Wickens, M.P., CARBon, J. \& SCHIMKE, R.T. (1979) Isolation of recombinant plasmids bearing cDNA to hen ovomucoid and lysozyme mRNAs. Journal of Biological Chemistry, 254, 9277-9283.

CANField, R.E. (1963) Sequence of human lysozyme. Journal of Biological Chemistry. 238, 2698-2270. 
Catovsky, D., Galton, D. \& Griffin, C. (1971) The significance of lysozyme estimations in acute myeloid and chronic monocytic leukaemia. British Journal of Haematology, 21, 565-580.

Collins, S.J., Bodner, A., Ting, R. \& Gallo, R.C. (1980) Induction of morphological and functional differentiation of human promyelocytic leukemia cells (HL-60) by compounds which induce differentiation of murine leukemia cells. International journul of Cancer, 25, 213-218.

Collins, S.J., Gallo, R.C. \& Gallagher, R.E. (1977) Continuous growth and differentiation of human myeloid leukaemic cells in suspension culture. Nature, 270, 347-348.

Collins, S.J., Ruscetti, F.W., Gallagher, R.E. \& GALLO, R.C. (1979) Normal functional characteristics of cultured human promyelocytic leukcmia cells (HL-60) after induction of differentiation by dimethylsulfoxide. Journal of Experimental Medicine, 149, 969-974.

Dayнoff, D. (1973) Atlas of Protein Sequence and Structure, Vol. 5, Suppl. 1, p. 533.

Driedger. P.E. \& Blumberg, P.M. (1980) Specific binding of phorbol ester tumor promoters. Proceedings of the National Academy of Sciences of the United States of America, 77, 567-571.

Fontana, J.A., Wright, D.G., Schiffman, E., Corcoran, B.A. \& Deisseroth, A.B. (1980) Development of chemotactic responsiveness in myeloid precursor cells: studies with a human leukemia cell line. Proceedings of the National Academy of Sciences of the United States of America, 77, 3664-3668.

Gallagher, R., Collins, S.. Trujillo. J.. McCredie, K., Ahearn, M., Tsai S., Metzgar, R., AuLAKH, G., Ting. R., Ruscetti, F. \& Gallo, R. (1979) Characterization of the continuous differentiating myeloid cell line (HL-60) from a patient with acute promyelocytic leukemia. Blood. 54, 713-733.

GORDON, S., TODD, J. \& COHN, Z. (1974) In vitro synthesis and secretion of lysozyme by mononuclear phagocytes. Journal of Experimental Medicine. 139, 1228.

Huberman, E. \& Callahan, M.F. (1979) Induction of terminal differentiation in human promyelocytic leukemia cells by tumor-promoting agents. Proceedings of the National Academy of Sciences of the United States of America. 76. 1293-1297.
Huberman, E., Weeks, C., Herrmann, A., CallahaM, M. \& SLAGA, T. (1981) Alterations in polyamine levels induced by phorbol diesters and other agents that promote differentiation in human promyelocytic leukemia cells. Proceedings of the National Academy of Sciences of the United States of America, 78, 1062-1066.

Miller, D.M., Turner, P., Neinhuis, A., Axelrod, D. \& Gopacakrishnan, T.V. (1978) Active conformation of the globin genes in uninduced and induced mouse erythroleukemia cells. Cell, 14, $511-521$.

Newburger, P.E., Baker, R.D., Hansen, S.L., DuncAN, R.A. \& GREeNberger, J.S, (1981) Functionally deficient differentiation of HL-60 promyelocytic leukemia cells induced by phorbol myristate acetate. Cancer Research, 41, 1861-1865.

OlsSon, l.L., Breitman, T.K. \& Gal.Lo, R.C. (1982) Priming of human myelold leukemic cell lines HL-60 and U-937 with retinoic acid for differentiation effects of cyclic adenosine 3':5'-monophosphate-inducing agents and a T-lymphocyte-derived differentiation factor. Cancer Research, 42, 3928-3933.

OlsSON, I. \& OlOFsson, T. (1981) Induction of differentiation in a human promyelocytic leukemic cell line (HL-60). Experimental Cell Research, 131, 225-230.

Osserman, E.F. \& LaWlor, D. (1966) Serum and urinary lysozyme (muramidase) in monocytic and monomyelocytic leukemia. Journal of Experimental Medicine, 124, 921-952.

Pinkus, G.S. \& SAID, J.W. (1977) Profile of intracytoplasmic lysozyme in normal tissues myeloproliferative disorders, hairy cell leukemia and other pathologic processes. American Journal of Pathology. 89, 351-362.

Rovera, G., O'Brien, T.G. \& Diamond, L. (1979) Induction of differentiation in human promyelocytic leukemia cells by tumor promoters. Science, 204, 868-870.

Rovera, G., Olashaw, N. \& Meo, P. (1980) Terminal differentiation in human promyelocytic leukaemic cells in the absence of DNA synthesis. Nature, 284, 60-70.

Sando, J.J., Hilfiker, M.L.. Salomon, D.S. \& FARRAR, J.J. (1981) Specific receptors for phorbol esters in lymphoid cell populations: Role in enhanced production of T-cell growth factor. 
Proceedings of the National Academy of Sciences of the United States of America, 78, 1189-1193.

Shoyab, M. \& Todaro, G.J. (1980) Specific high affinity cell membrane receptors for biologically active phorbol and ingenol esters. Nature, 288 , 451-455.

Solsted, M.E. \& Martinez, R.J. (1978) Lysozyme. primary bactericidin in human plasma-serum active against $\mathrm{B}$. subticis. Infection and Immunology, 20, 782-791.

Tarella, C., Ferrero, D., Gallo, E., Pagliardi, G.L. \& RuscetTI, F.W. (1982) Induction of differentiation of HL- 60 cells by dimethyl sulfoxide: evidence for a stochastic model not linked to the cell division cycle. Cancer Research, 42, 445-449.

TODD, R.F., III, GRIFFIN, J.D., RITZ, J., NADLER, L.M., Abrams, T. \& Schlossman, S.F. (1981) Expression of normal monocyte-macrophage differentiation antigens on HL60 promyelocytes undergoing differentiation induced by leukocyte-conditions medium or phorbol diester. Leukemia Research, 5, 491-495.

Yam, L., LI, C.Y. \& CRosby, W.H. (1971) Cytochemical identification of monocytes and granulocytes. American Journal of Clinical Pathology, 55, 283-290. 